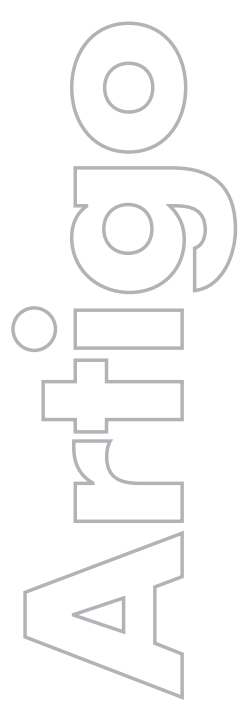

revista

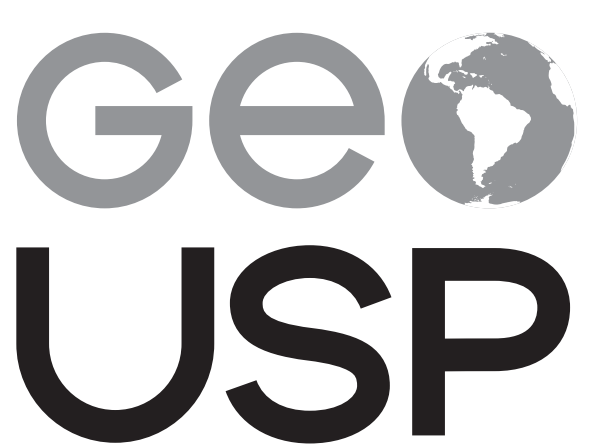

espaço e tempo

Volume $22 \cdot n^{\circ} 1$ (2018)

\section{meio técnico- científico-informacional, os equipamentos de imagem-diagnóstico e a desigualdade em saúde no Brasil}

\author{
Oseias da Silva Martinuci \\ Universidade Estadual de Maringá \\ Raul Borges Guimarães \\ UNESP - Pres. Prudente
}

p. $076-095$

Como citar este artigo:

MARTINUCI, O. S.; GUIMARÃES, R. B. O meio técnico-científico-informacional, os equipamentos de imagem-diagnóstico e a desigualdade em saúde no Brasil. Geousp - Espaço e Tempo (Online), v. 22, n. 1, p. 076-095, mês. 2018. ISSN 2179-0892.

Disponível em: <http://www.revistas.usp.br/geousp/article/ view/118718>. doi: http://dx.doi.org/10.11606/issn.2179-0892. geousp.2018.118718.

\section{(c) (i) (3)}

Este artigo está licenciado sob a Creative Commons Attribution 4.0 License. 


\title{
O meio técnico-científico-informacional, os equipamentos de imagem-diagnóstico e a desigualdade em saúde no Brasil
}

\section{Resumo}

Este artigo discute as desigualdades em saúde no Brasil tomando como referência o conhecimento geográfico do território nacional. Para isso, considera como se combinam as mudanças econômicas, demográficas, sociais e políticas das últimas décadas com as velhas estruturas territoriais brasileiras, condicionando diferentemente nos lugares o processo saúde-doença, bem como os modos de obter saúde. Analisa a distribuição territorial de dois dos mais sofisticados equipamentos de imagem-diagnóstico: tomógrafos computadorizados e aparelhos de ressonância magnética. A análise sugere que esses objetos raros se somam às demais concentrações territoriais, nem sempre em consonância com as necessidades da população ou com as demandas regionais, comprometendo seriamente os princípios de equidade, universalidade e integralidade do Sistema Único de Saúde, com impacto direto na própria cidadania.

Palavras-chave: Território. Situação geográfica. Transição em saúde. Tecnologia médica. Desigualdades em saúde.

\section{The technical-scientific-informational environment, diagnostic-imaging equipment and health inequality in Brazil}

\begin{abstract}
This article discuss the relationship between health inequalities and geographical approaches in order to understand how economic, demographic, social and political changes combined with old Brazilian territorial structures. The focus of the work is the analysis of the territorial distribution of two of the most sophisticated diagnostic imaging equipment: computerized tomographs and magnetic resonance imaging devices. The analysis suggests that these technical objects add up to territorial concentrations, not always in line with the needs of the population and with the regional demands, seriously compromising the principles of equity, universality and integrality of the National Policy Health, which impacts citizenship itself.
\end{abstract}

Keywords: Territory. Geographic location. Health transition. Medical technology. Health inequalities. 


\section{Introdução}

Em pleno século XXI o Brasil continua a ser um dos mais desiguais do mundo. Tal desigualdade está assentada não somente na concentração de renda, mas sobretudo na diferenças de acesso aos direitos sociais.

Além da concentração social da riqueza nas mãos de alguns, origem dos muitos privilégios, não podemos ignorar o papel de sua distribuição espacial. A dimensão continental do Brasil e sua complexa configuração territorial (disposição dos sistemas naturais e sistemas técnicos na formação socioespacial) impõe a análise geográfica da cidadania. A configuração territorial brasileira e as rugosidades espaciais (isto é, a história da técnica acumulada no espaço) levaram a uma difusão concentrada dos objetos e ações necessárias à corporificação dos direitos (Ribeiro, A., 2005).

Tendo essas características do espaço brasileiro em mente, interessa-nos analisar a distribuição desigual de equipamentos médicos sofisticados incorporados ao Sistema Único de Saúde (SUS). Afinal, a instituição do SUS com a Constituição Federal de 1988 foi um importante avanço, ao estabelecer que a saúde como um direito de todos, orientado pelos princípios de universalidade, integralidade e equidade (Barata, 2009). Lembram Nunes et al. (2014) que - SUS alcançou inúmeros avanços, mas a relação da população brasileira com os serviços de saúde ainda continua desigual. A desigualdade é ainda mais marcante quando consideramos os serviços mais sofisticados, que exigem aparato tecnológico de ponta, como é o casos dos aparelhos de imagem-diagnóstico, particularmente, a ressonância magnética e o tomógrafo computadorizado.

O tema das desigualdades nos estudos sobre saúde não é novo. Como destaca Barata (2009), a preocupação já estava presente no século XIX, com Engels quando estudou as condições da classe trabalhadora em Londres, e com John Snow, quando pesquisou a disseminação da cólera na mesma cidade. Mais recentemente, Barros (2017) afirma que houve uma ampliação das preocupações com os impactos das desigualdades no processo saúde-doença, sobretudo a partir da década de 1990. Em 1996, por exemplo, a Organização Mundial da Saúde lançou uma iniciativa para incentivar o enfretamento das desigualdades em saúde. Desde então, as pesquisas e publicações envolvendo o tema cresceram de modo significativo.

Com isso, podemos considerar como as desigualdades em diferentes dimensões afetam a saúde da população. As pesquisas conduzidas por Travassos et al. (2000) evidenciaram que as desigualdades afetam a equidade no acesso aos serviços de saúde. Neri e Soares (2002), por exemplo, afirmam que as chances de alguém com plano de saúde acessar esses serviços é $452 \%$ maior que aqueles que não o possuem. Consequentemente, impacta-se a própria expectativa de vida, principalmente das classes sociais de menor renda. $\bigcirc$ trabalho desenvolvido por House, Kesseler e Regula (1990), por exemplo, evidenciou que os pobres adoecem mais cedo. Os autores mostraram que certas doenças crônico-degenerativas acometem as classes de menor rendimento cerca de 30 anos antes que as de maior rendimento. Mesmo a desigualdade econômica considerada de modo mais simples representa uma vida mais curta para as populações mais pobres. Numa obra recente, Joseph Stiglitz (2016) afirma que o aumento da desigualdade nos EUA e a distribuição desigual das vantagens e 
desvantagens entre a população após a crise do setor financeiro em 2008 representaram alguns anos a menos na expectativa de vida dos mais pobres. Segundo o autor, a diferença na expectativa de vida entre os mais pobres e aqueles que estão no topo é de aproximadamente 10\%, ou quase oito anos (Stiglitz, 2016, p. 73).

Num sentido mais amplo, a desigualdade entre lugares pesa enormemente na saúde dos indivíduos. Ao estudar os dados da Pnad 1998, Neri e Soares (2002) detectaram que áreas de menor densidade de serviços médicos reduzem a probabilidade de acesso. Na palavra dos autores, menores densidades geram custos de oportunidade (como a distância, tempo e custos de deslocamento) que influenciam a decisão de acessar os serviços. Nesse sentido, é possível dizer que, além de mutilar a cidadania, a desigualdade faz mal à saúde.

Nesse contexto, o conhecimento geográfico acerca da desigualdade na saúde tem sido fundamental. dado a sua contribuição, ainda que de maneira tímida. Os trabalhos desenvolvidos por estudiosos das mais diversas formações já têm indicado que o espaço geográfico tem um forte peso na determinação das condições de saúde. Para Barata (2009, p. 39), por exemplo, o espaço geográfico "é um poderoso determinante do estado de saúde das populações". No âmbito da geografia, um dos mais importantes esforços para entender a distribuição desigual dos recursos em saúde no território brasileiro pode ser creditado a Eliza Almeida (2005), geógrafa que fez uma ampla leitura da estruturação do sistema de saúde no Brasil numa abordagem eminentemente geográfica, revelando as dinâmicas concentradoras dos recursos em saúde no território e, consequentemente, as desigualdades a elas associadas.

$\bigcirc$ estudo das desigualdades em saúde pelos geógrafos, entretanto, ainda está aquém das possibilidades. Guimarães (2016) em uma recente análise das publicações em três das principais revistas de saúde coletiva do Brasil: Revista de Saúde Pública, Cadernos de Saúde Pública e Saúde e Sociedade, revelou que, do total de publicações relativas à geografia, apenas 6,2\% tratam do problema das desigualdades em saúde.

Esse artigo pretende, portanto, contribuir com o debate sobre as desigualdades em saúde numa perspectiva de análise geográfica, focando o problema da distribuição dos equipamentos de ressonância magnética e tomografia computadorizada. Num país tão complexo como o Brasil, os geógrafos devem dar mais atenção às desigualdades em saúde. Por isso, devem estabelecer alguns parâmetros de análise baseados numa consistente teoria geográfica.

\section{Possibilidades de leitura geográfica da saúde e da tecnologia médica}

A leitura delineada aqui baseia-se na teoria do espaço geográfico de Milton Santos. Tratando da geografia como ciência e de seu objeto de estudo, o espaço geográfico, esse geógrafo forneceu um conjunto de conceitos e categorias que nos permite hoje estudar temas tão complexos como a saúde. Sua teoria nos permite uma visão integral dos problemas relativos aos direitos dos cidadãos.

A saúde é uma condição primária da existência humana e, como tal, se relaciona com todas as dimensões da vida. Interfere no trabalho, no ensino, nas relações interpessoais e, de um modo mais amplo, nas condições de cidadania dos sujeitos. Em sua obra $A$ condição humana, Hannah Arendt (2008) nos lembra que o homem é condicionado pelo produto de seu trabalho, pelo artificialismo, pelas coisas. Assim, tudo que entra em contato com ele condicio- 
na sua existência. Nesses termos, podemos dizer que, à medida que cria objetos cada vez mais sofisticados rapidamente incorporados a consultórios, hospitais e serviços de apoio diagnóstico (como os equipamentos de tomografia computadorizada e de ressonância magnética), a tecnologia médica condiciona nossa existência. Ao mesmo tempo, interfere no nosso entendimento do que é a saúde e como obtê-la. Cresce cada vez mais o desejo de tratar e de ser tratado por modernos equipamentos médicos, sedimentando uma compreensão de saúde baseada na cura e estreitamente associada à ideia de doença (Antas Jr; Almeida, 2015). Caracterizam-se uma tecnosfera (a presença crescente de aparelhos sofisticados no fazer médico) e uma psicosfera (crescente associação, frequentemente irrefletida, entre modernos objetos médicos e uma vida mais saudável) que pressionam cada dia mais o sistema de saúde.

A imagem de medicina que está se desenvolvendo, progressivamente, amparada pela tecnologia, é a de um trabalho altamente complexo, prestigiado e com baixo nível de falibilidade. Busca-se o especialista que mecaniza gradativamente sua prática, dando ao usuário a imagem de um suposto nível de excelência, muitas vezes, não necessário. Nesses termos, o recorte da saúde como um fenômeno de estudo, deve ser sempre cuidadoso. Por isso, a estratégia adotada aqui é abordar a saúde a partir da perspectiva geográfica. Para analisar apropriadamente a questão da saúde a partir da perspectiva geográfica, particularmente, temos por base dois conceitos atinentes à teoria geográfica: totalidade concreta e situação geográfica.

Discutindo ideia de totalidade, a geógrafa María Laura Silveira (1999) adverte que cabe ao geógrafo arrolar os elementos que the parecem fundamentais para analisar o complexo de relações que não é dado por todos os fatos, todos os aspectos, todas as coisas, todas as relações. Assim, pode-se atingir aquilo que Kosik (1989, p. 36) chamou de "totalidade concreta". A situação geográfica, por sua vez, pode ser apreendida escolhendo-se uma variável chave e a partir dela reconstruírem-se as relações e se lançar luz no fenômeno e em sua complexidade. A situação geográfica é, portanto, mais que uma parte ou recortes do território; é um conjunto de relações, um nó de verticalidades e horizontalidades, de solidariedades orgânicas próprias ao lugar e solidariedades organizacionais advindas de ordens distantes (Silveira, 1999, p. 27). A situação geográfica está diretamente ligada à ideia de evento, compreendido como "unidade do movimento de totalização do espaço geográfico" (Silveira, 1999, p. 26). Os eventos são normas, formas, objetos, agentes e ações que se geografizam nos lugares, passando da latência à existência. A combinação diferenciada dos eventos nos lugares é que vai conferir singularidades aos espaços.

Atualmente, o conceito de situação geográfica tem sido influenciado e enriquecido pela leitura dos filósofos existencialistas, a partir da qual se pode reconhecer a diversidade dos lugares e evitar os perigos da condução do múltiplo à unidade, exercitado pela ciência para tornar o mundo compreensível (Cataia; Ribeiro, L., 2015, p. 13). Ao mesmo tempo em que permite reconhecer contextos específicos, torna imperativa a consideração das escalas de ação, dos agentes e das relações com as coisas e com os homens. Com o advento da globalização, favorecido pelo rápido desenvolvimento das técnicas de circulação (de pessoas, mercadorias e informações), a situação geográfica chama a si a consideração da totalidade, alçando-a a um status explicativo fundamental no período atual. 
A técnica, por sua vez, não é a adaptação do sujeito ao meio, mas o contrário, a adaptação do meio aos seres humanos, uma vez que são os únicos que têm projetos e são capazes de executá-los (Ortega y Gasset, 1963). Logo, o meio, por si só, não existe, ele é meio de algo ou alguém. Trata-se de um espaço relacional, inseparável das experiências intersubjetivas e avança juntamente com elas. Pensando desse ponto de vista, todas as relações que se dão entre os seres humanos e o meio são técnicas, e daí deriva o modo como se configuram objetos e ações em cada lugar.

Quando um objeto técnico é instalado num determinado lugar, as normas estabelecidas em lugares mais distantes se impõem, seja nos procedimentos técnicos a serem adotados com os equipamentos, assim como nas relações de trabalho envolvidas no seu uso (Santos, 1996, p. 182). É por isto que a norma é um dos fundamentos principais da ordem sistêmica. São os procedimentos organizacionais (como a regionalização da saúde pelos gestores do SUS) e os objetos técnicos instalados nos diferentes lugares (serviços de saúde com diferentes níveis de complexidade, por exemplo) que normatizam o território e, portanto, a vida das pessoas.

Dessa maneira, o setor saúde estaria submetido a esta ordem sistêmica cuja norma definida pelos grandes agentes já estaria predeterminada na receita de medicamentos, nos procedimentos técnicos para uso de equipamentos terapêuticos e de apoio diagnóstico e mesmo nos temas que seriam mais relevantes para as pesquisas acadêmicas. Não por outra razão, o mercado da medicina, especialmente aquela de alta tecnologia, que se apropria de boa parte dos fundos públicos (Guimarães, 2009, p. 108), torna as questões epidemiológicas e de saúde e ambiente periféricas na agenda das políticas de saúde. Ademais, a incorporação de novas tecnologias nem sempre se dá com a certeza de seus benefícios para os pacientes (Novaes; Novaes, 1994; Trindade, 2013), mas se as impõem porque portam promessas de uma saúde melhor para as populações.

Se por um lado, esses objetos médicos modernos se estabelecem com a promessa de fornecer mais saúde, por outro lado, não estão ao alcance de todos os cidadãos, uma vez que, como veremos, se distribuem desigualmente no território. Cobertura e acessos diferenciais, em função da difusão desigual dos objetos e ações em saúde no território brasileiro, tendem a comprometer o ideal de cidadania e, em particular, o ideal de "saúde para todos", como preconizado pelo SUS. A análise da geografia dos equipamentos de imagem-diagnóstico possibilita considerar a saúde um problema de cidadania. Lembra Milton Santos (2007) que, para compreender integralmente a cidadania, é necessário compreender como se dão a disseminação e o uso dos direitos no território. Para promover a cidadania, portanto, é preciso planejar as políticas públicas territorialmente.

Para melhor avaliar a adequação ou inadequação da atual distribuição dos equipamentos de imagem diagnóstico no Brasil, é preciso destacar alguns elementos que constituem o atual quadro demográfico e epidemiológico no território. Como é sabido, o uso da ressonância magnética e do tomógrafo computadorizado tem sido estreitamente associado ao diagnóstico de doenças próprias do envelhecimento como as crônico-degenerativas, sobretudo as relativas ao aparelho circulatório e às neoplasias. Por isso, é importante tratar de alguns aspectos das recentes transformações no território brasileiro, reunidos naquilo que tem sido 
chamado de "transição em saúde". Esses aspectos constituem os eventos que dão condições e viabilizam para a geografização dos agentes globais do mercado de equipamentos de imagem-diagnóstico no território brasileiro, ainda que de modo desigual.

\section{Transição em saúde}

As transformações epidemiológicas e demográficas são duas importantes dinâmicas catalisadoras das mudanças no perfil de saúde dos brasileiros. Apesar de serem ressaltadas com mais frequência, tais mudanças não se devem única e exclusivamente a aspectos epidemiológicos e demográficos. Por essa razão, tanto Lerner (1973) quanto Frenk et al. (1991) e, também, Chaimowicz (1997) preferem falar em "transição em saúde" ao invés de "transição epidemiológica". O conceito de transição em saúde tem a capacidade de traduzir mais amplamente o conjunto de mudanças ocorridas em determinada população, do qual a transição epidemiológica e a transição demográfica são apenas dois dos componentes. Entre os demais, podemos citar: a dimensão "ambiental", a dimensão territorial e sua relação com a distribuição de ações e objetos em saúde, que determinam o acesso aos serviços, o processo de urbanização do território e as mudanças decorrentes, a existência/inexistência de infraestrutura de saneamento básico, a ampliação do acesso aos diferentes níveis de ensino, a mudança do perfil das atividades laborais que, no mundo moderno, tendem ao sedentarismo, ampliando o risco de doenças crônico-degenerativas, a mudança dos hábitos alimentares etc. Diante da impossibilidade de avaliar aqui todos esses processos, destacam-se os aspectos demográficos e epidemiológicos e a interferência da dimensão espacial.

Desde a década de 1960, diversos indicadores demográficos têm registrado várias mudanças. A taxa anual de crescimento da população, que atingiu seu ápice em 1960, passou de 2,99\% ao ano para 1,17\% em 2010. Uma redução a menos da metade. A taxa de fecundidade que, também, atinge seu ápice no ano de 1960, passou de 6,3 filhos por mulher para 1,9 em 2010, ficando, portanto, abaixo do nível de reposição populacional. Outro importante indicador demográfico, a expectativa de vida dos brasileiros, ganhou um importante incremento. Passou de 54 anos, em 1960, para 73 em 2010. Recentes informações do Instituto Brasileiro de Geografia e Estatística (IBGE) dão conta de que a expectativa de vida do brasileiro já atingia 75,8 anos em 2017. Esse conjunto de mudanças gerou alteração na estrutura da pirâmide etária, entre 1960 e 2010, com o estreitamento da base e o alargamento da parte central e do topo (Figuras 1 e 2). Se por um lado, isso certamente reflete um avanço importante nas condições de vida, por outro, essas mudanças, associadas à precariedade dos serviços de saneamento básico e dificuldade no acesso aos cuidados básicos de saúde, conferem significativas particularidades ao caso brasileiro. As desigualdades sociais inerentes a nossa sociedade, que são sobretudo territoriais, se manifestaram, em cada ponto do país, com distintas combinações. Apesar disso, é preciso reconhecer os avanços que ocorreram para importantes parcelas da população e, ao mesmo tempo, atentar para o fato de que muitos dos dilemas vividos pela sociedade é, também, resultado do progresso (Lacoste, 2008). Bobbio (2004, p. 35) acrescenta, por sua vez, que esses progressos produzem novas demandas, levando para frente o horizonte dos direitos sociais. 
Figura 1 - Pirâmide etária - 1960

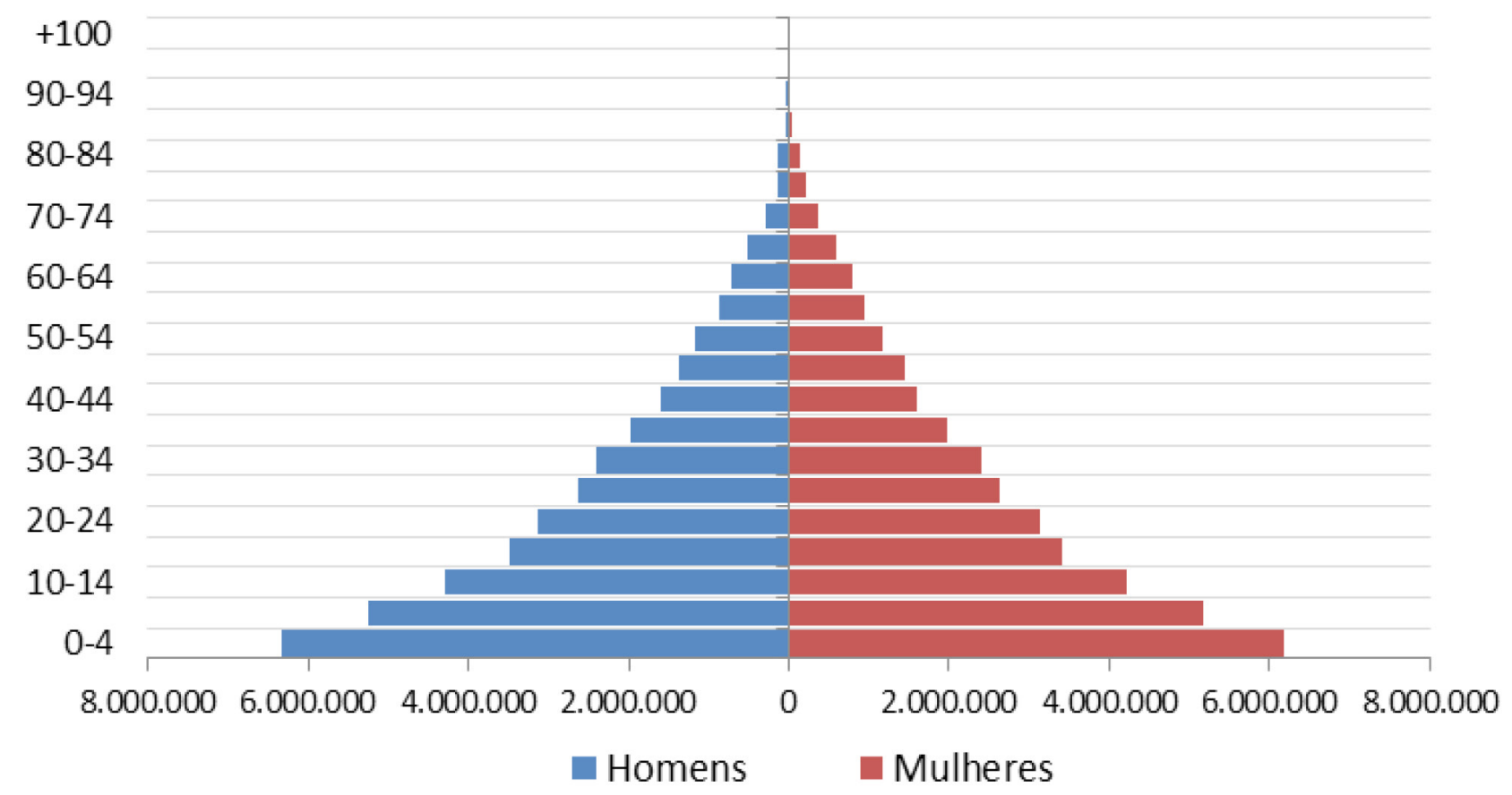

fonte: IBGE (2013).

organização: Oseias S. Martinuci e Raul B. Guimarães, 2013.

Figura 2 - Pirâmide etária - 2010

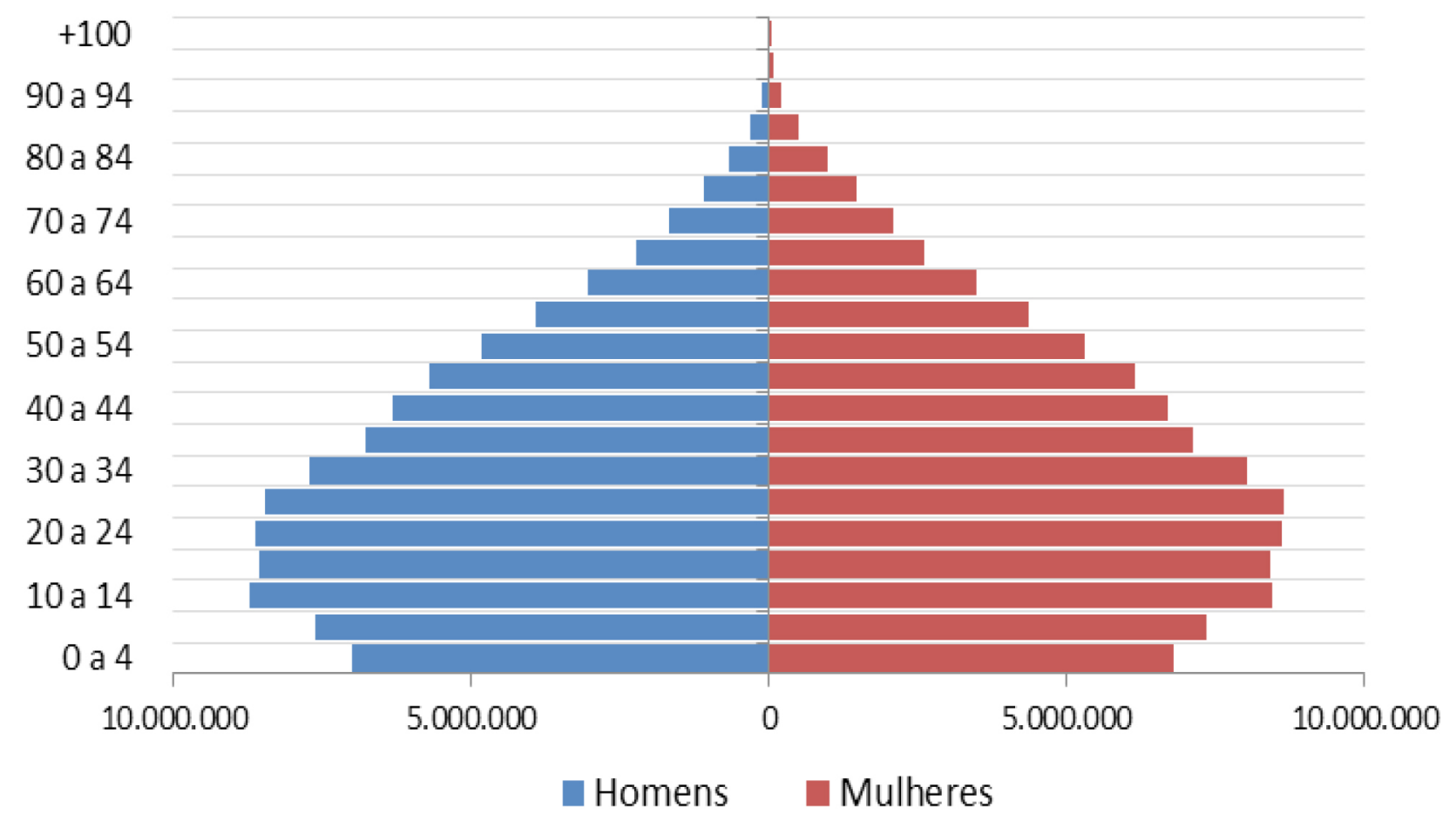

fonte: IBGE (2013). organização: Oseias S. Martinuci e Raul B. Guimarães, 2013.

De acordo com Simomura (2013), o envelhecimento populacional compreende dois aspectos simultâneos. O primeiro é o aumento relativo do peso dos idosos se comparado aos outros contingentes populacionais, como crianças, jovens e adultos. $\bigcirc$ segundo, o próprio en- 
velhecimento biológico. Devido aos avanços sociais, em especial nas áreas de assistência e tecnologia médica, aumenta a possibilidade de cura e se reduz a mortalidade precoce ligada a uma série de doenças, sejam elas transmissíveis ou crônico-degenerativas. Salienta a autora que os cuidados de saúde necessários à população idosa são diferentes daqueles de outros grupos etários, em função das incapacidades geradas nos processos degenerativos e requerem investimentos consideráveis em recursos físicos, medicamentos, pessoal capacitado e procedimentos tecnológicos.

A partir dos 50 anos, aumenta a incidência de doenças crônico-degenerativas como, por exemplo, neoplasias e doenças do aparelho circulatório (Martinuci, 2013). À medida que a população envelhece, inverte-se a pirâmide etária, em função de avanços na infraestrutura sanitária e acesso a serviços sociais básicos, e também a predominância de doenças infectocontagiosas por doenças crônico-degenerativas, em especial as neoplasias. Como se pode observar na Figura 3, em 1980 o grupo da causa de mortes por doenças infecciosas e parasitárias correspondia a 10,39\%, enquanto as neoplasias correspondiam a 11,80\%. Vinte anos depois, as doenças infecciosas e parasitárias passam a responder por 4,29\% do total de mortes e as neoplasias por $15,74 \%$.

\section{Figura 3 - Mortalidade proporcional por neoplasias ou doenças infecciosas e parasitárias - 1980-2010}

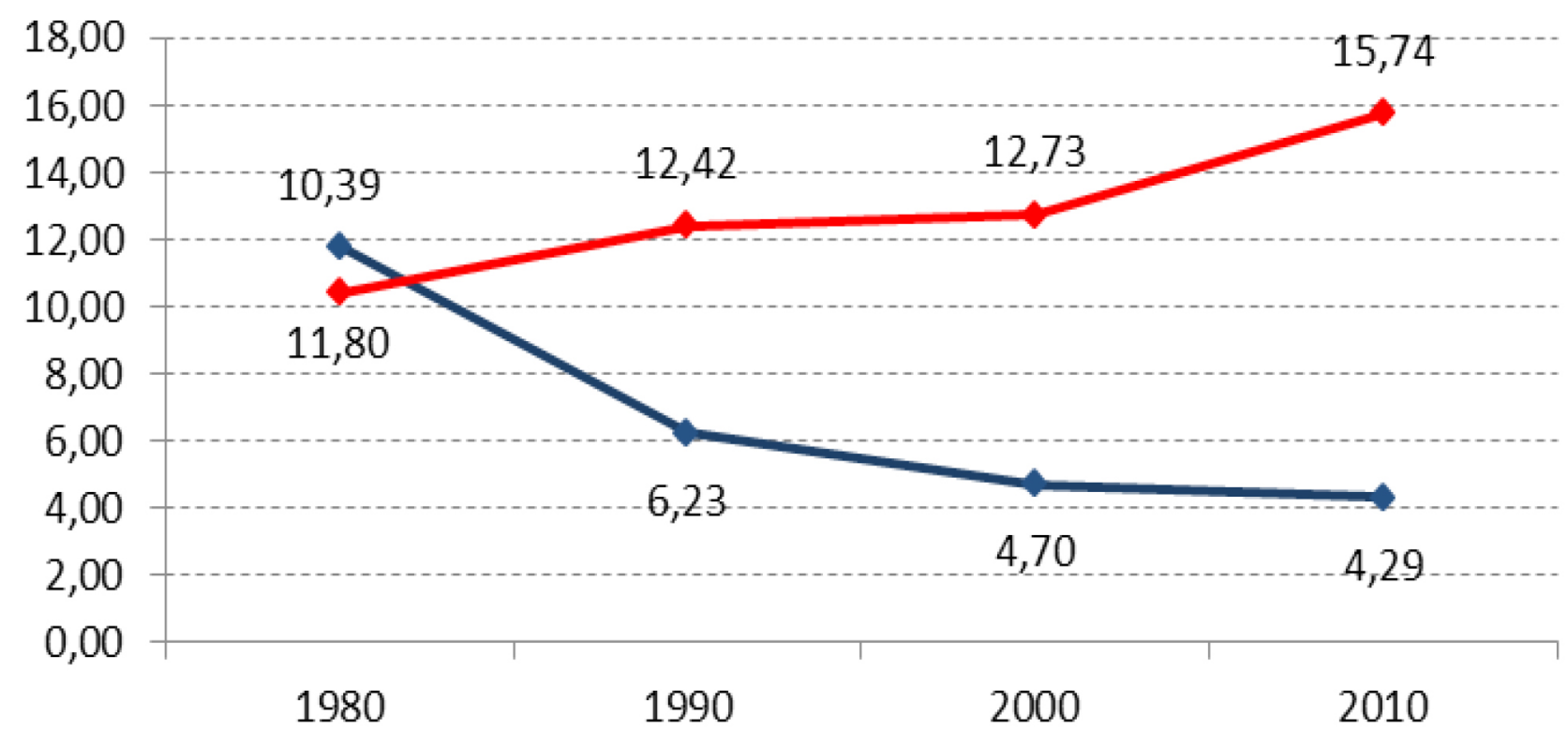

—Doenças infecciosas e parasitárias — Neoplasias

fonte: MS (2013). organização: Oseias S. Martinuci, 2013.

A transição em saúde, para assumir concretude, deve ser expressa, também, e, principalmente, como uma transição geográfica em saúde, pois as condições de saúde variam conforme os lugares e conforme a combinação de diferentes fenômenos no espaço geográfico. Nesse sentido, a situação geográfica, ou seja, a combinação de diferentes eventos, sejam eles 
econômicos, sociais, demográficos, técnicos etc., conferem singularidade às condições de saúde em cada canto do país. Por essa razão, pode-se dizer, conforme Oliveira, Carvalho e Travassos (2004, p. S308), que não é possível uma solução única para o país. Às diferenças espaciais, resultado das diversas combinações de eventos geográficos, somam-se as desigualdades sociais e territoriais brasileiras.

A espacialidade da população idosa, especialmente com mais de 50 anos, mais sujeita a doenças crônico-degenerativas, está caracteristicamente relacionada ao processo de ocupação do território brasileiro, por um lado, e à disposição das densidades técnicas, por outro. Esse Brasil idoso se concentra sobretudo na região Sul e em grande parte da região Sudeste, excetuado o norte de Minas Gerais, mas também em parte do interior da região Nordeste. Destaque importante deve ser dado à configuração de dois eixos de transformação que, ao lado de consolidação de eixos técnicos e de infraestruturas importantes, seguem, também, mudanças no conteúdo social dos espaços sob sua influência. Trata-se dos eixos que se estendem do Sudeste à região de Marabá, no Pará e à região de Porto Velho, em Rondônia (Mapa 1).

\section{Mapa 1 - Percentual da população com mais de 50 anos - 2010}

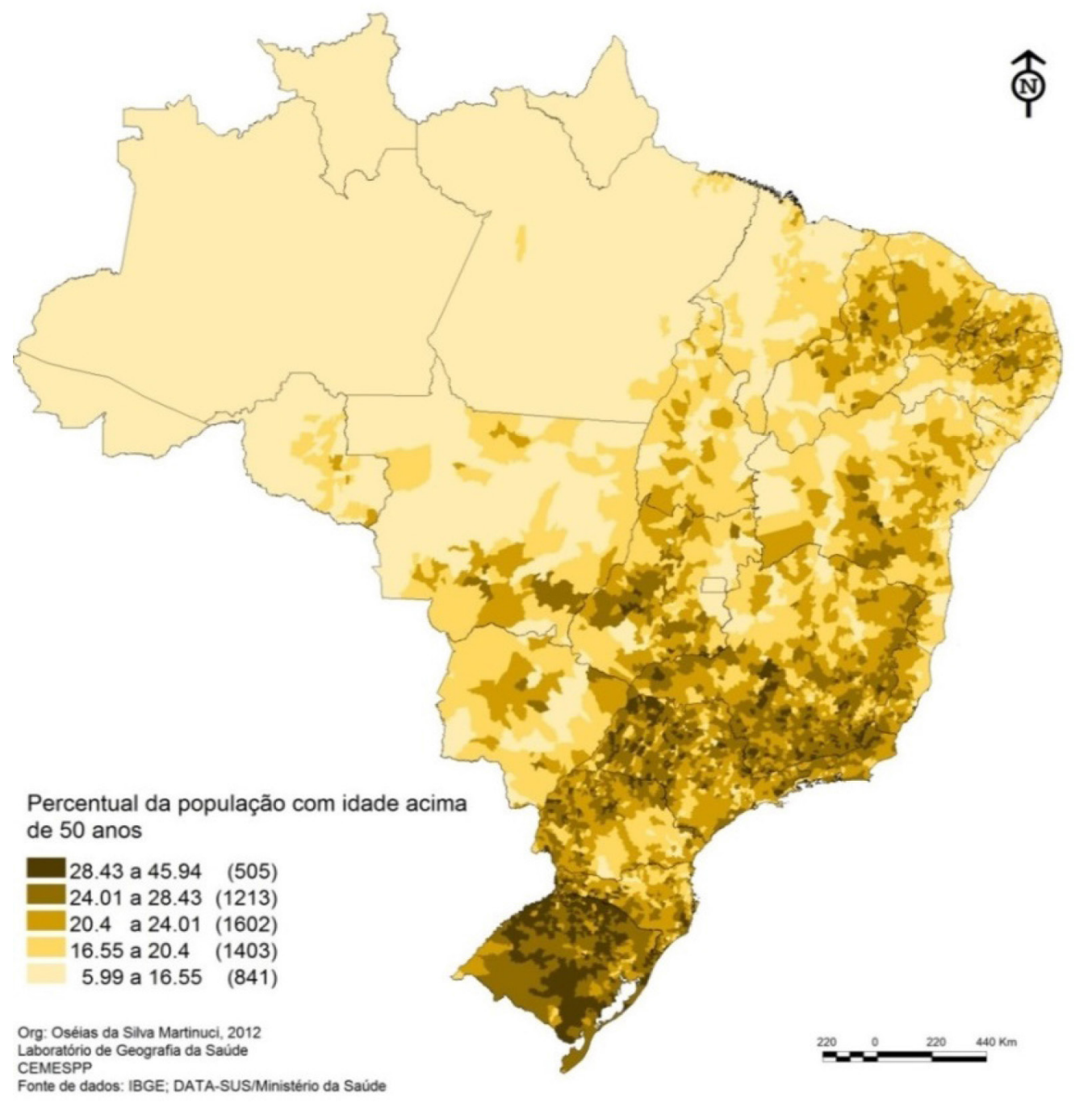

fonte: IBGE (2008). 
A distribuição das pessoas com mais de 50 anos no território brasileiro, ao lado de outros processos como a urbanização e a mudança do perfil laboral, entre outros, está associada ao fortalecimento e à concentração das neoplasias. Os Mapas 2 e 3 são bastante sugestivos e representam uma parte dos efeitos da transição em saúde pela qual passa o país, que é também uma transição geográfica em saúde.

\section{Mapa 2 -}

Mortalidade por neoplasias, 1991

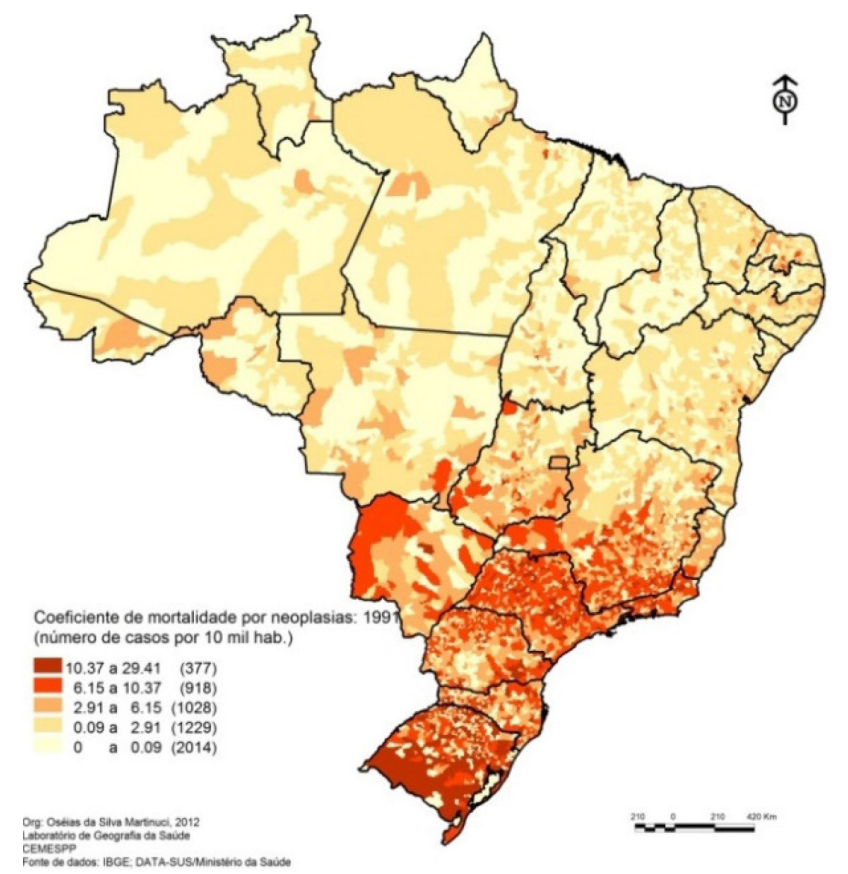

fonte: MS (2013).

\section{Mapa 3 -}

Mortalidade por neoplasias, 2010

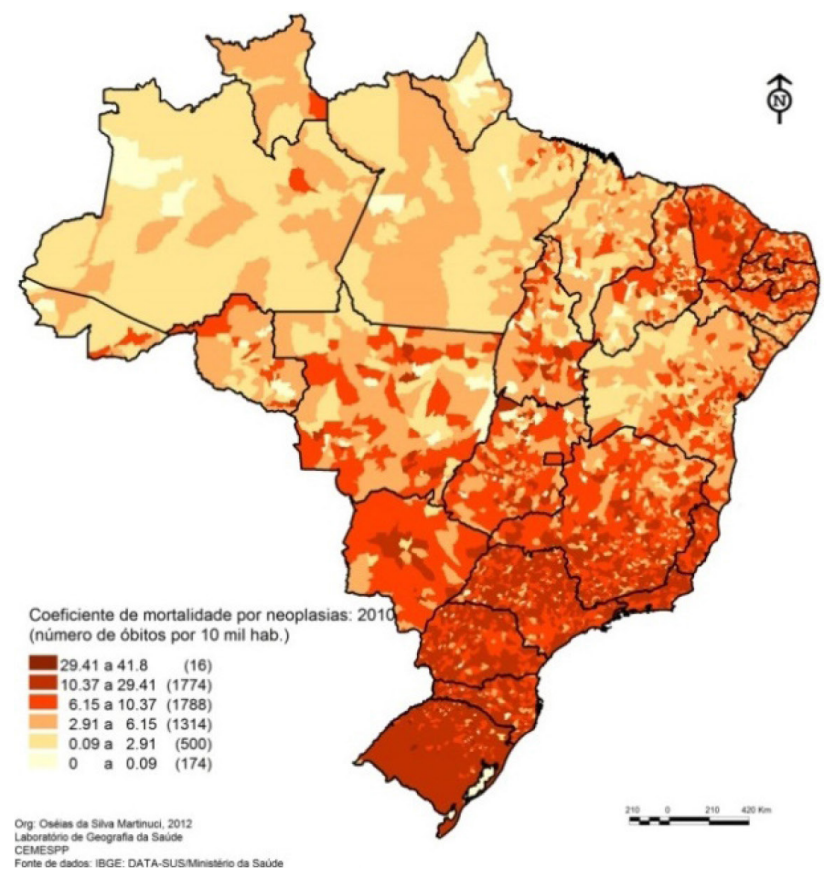

fonte: MS (2013).

organização: Oseias S. Martinuci, 2013.

Pode ser facilmente verificada a alta correlação espacial entre as regiões mais envelhecidas do Brasil (Mapa 1) e a presença dos mais elevados coeficientes de neoplasias (Mapas 2 e 3).

As transformações demográficas, que acarretam, também, transformações na condição de saúde dos cidadãos, nem sempre estão acompanhadas, do ponto de vista espacial, dos cuidados de saúde necessários a uma população que está em processo acelerado de envelhecimento. $\bigcirc$ alargamento espacial da incidência das doenças crônico-degenerativas ocorrido nesse pequeno período considerado (1991-2010) indica, também, uma frente que logo mais passará também por importantes transformações epidemiológicas, para as quais o Estado brasileiro precisa estar preparado, no sentido de atender as demandas que surgirão, principalmente, em regiões onde a mobilidade populacional e a fluidez territorial são bastante reduzidas se comparadas com as regiões Sul e Sudeste, onde se concentra a maior parte dos sistemas de engenharia destinados ao transporte e às comunicações.

O ideal de acesso aos serviços de saúde para necessidades iguais preconizados no SUS, entretanto, tende a ser comprometido, em demasia, pela caracterização do sistema de saúde como um mercado e da medicina como um produto (Mota, 2003). No Brasil, país de dimen- 
sões continentais, onde a distância ainda continua sendo um problema de existência e onde há uma brutal desigualdade na distribuição dos sistemas de comunicação e transporte, associados à desigualdade econômica, o comportamento do sistema de saúde como um mercado, exige soluções que levem em consideração o espaço geográfico, tomado em sua complexidade.

Entretanto, para pensar nas soluções que caminhem no sentido da equidade territorial, é preciso levar em conta como a produção do espaço geográfico condiciona a distribuição dos objetos e ações e, por consequência, as decisões políticas, que não podem ser alheias aos conteúdos do território.

\section{Rugosidades espaciais condicionam a localização de objetos e ações em saúde}

As rugosidades espaciais, resultantes da cristalização de ações de épocas pretéritas limitam, possibilitam e condicionam a ação. Portanto, as decisões políticas e as ações decorrentes não podem ignorar a estrutura espacial preexistente. De acordo com Milton Santos (2008, p. 173) "o espaço é uma forma que não se desfaz paralelamente às mudanças dos processos, pelo contrário, alguns processos se adaptam às formas preexistentes".

No mundo globalizado, os objetos modernos têm um conteúdo cada vez mais dependente de agentes e ações externos ao lugar. Como sabemos, a medicina é uma das áreas em que o desenvolvimento de tecnologias é cada vez mais rápido. $\bigcirc$ setor de equipamentos de imagem-diagnóstico é um dos setores de ponta da indústria médica mundial. Esse, particularmente, está dominado por grandes corporações globais como a Siemens Medical Solutions, Philips Medical Systems e a General Electric Healthcare, que têm internalizado parte de sua produção no território nacional para ter amplo acesso a um mercado ainda cativo, bem como às facilidades de financiamento pelos bancos públicos que só são possíveis para produtos fabricados no Brasil. De acordo com David (2011), para ampliar sua presença no mercado interno, essas grandes corporações têm adquirido empresas do setor nacional e se implantado em lugares onde a situação geográfica é mais favorável tanto para o escoamento da produção quanto para a obtenção de mão de obra qualificada.

Alguns eventos foram particularmente importantes para atrair a atenção dessas grandes empresas. A situação geográfica particularmente interessante do Brasil o torna um espaço estratégico como plataforma de ampliação do mercado de consumo dos equipamentos de imagem-diagnóstico. A intensificação das relações do Brasil com os países da América Latina, da África e da Ásia foi importantíssima como incentivo a mais às relações comerciais (Souza Neto, 2011; Coelho, 2010; Morais; Saad-Filho, 2011). A diversificação das relações comerciais do Brasil abriu um canal importante não só de resistência maior à crise financeira eclodida nos países centrais em 2008, mas também de acesso a mercados emergentes. A crise foi, em parte, responsável pela migração de certos capitais para mercados emergentes, entre eles, o Brasil. De acordo com um relatório da Associação Brasileira de Desenvolvimento Industrial (ABDI, 2008), entre 1999 e 2006, houve uma redução de $43 \%$ para 27\% das exportações estadunidenses. O relatório destaca que "longe de ser uma perda de vigor, tal mudança se deve a uma intensificação de uma estratégia de descentralização de grandes fabricantes que instalaram plantas em outros países a partir quais abastecem o mercado mundial" (ABDI, 2008, p. 50). Mais recentemente, esse processo de transferência de capitais e plantas industriais tem acontecido no setor de equipamentos médicos (David, 2011). 
Outro fator desse interesse crescente pelo mercado brasileiro é a ampliação da classe média (Neri, 2010), mais precisamente, aquela fatia da população que está inclinada e tem condições de comprar serviços médicos privados. Os dirigentes das áreas de saúde das corporações citadas, já se pronunciaram em inúmeras ocasiões por meio da imprensa brasileira, afirmando o potencial de lucro para o setor de equipamentos médicos no Brasil. De acordo com essas corporações a participação dos países emergentes na economia mundial deve mais do que dobrar no período 1999-2020, passando de 7,8\% para 16,1\%, o que significa grandes expectativas de lucros para o setor de equipamentos médicos.

Outra importante transformação está intimamente ligada com o processo de envelhecimento da população brasileira, tratado na seção anterior, que, associado à mudança do perfil laboral e do perfil epidemiológico, tende a exigir cada vez mais uma medicina assessorada por modernos equipamentos médicos.

Numa matéria veiculada no jornal Valor Econômico em 29 de março de 2012, o diretor da área de saúde da General Electric Healthcare deu os fatores levados em conta para a implantação de novas fábricas no Brasil: o envelhecimento da população e a expansão da classe média, grandes responsáveis pela elevação da demanda por equipamentos sofisticados.

Esses poucos elementos mostram que a situação geográfica é essencial para as escothas espaciais. Os grandes agentes da economia global agem em consonância com o conteúdo técnico (sistemas de engenharia, infraestruturas fundamentais para garantir fluidez material e imaterial ao mercado global de equipamentos médicos), com o conteúdo normativo (benefícios financeiros e isenções fiscais), com a configuração territorial (disposição e articulação dos objetos naturais e artificiais). Para a realização do mundo e a geografização dos projetos, é imprescindível considerar o conteúdo dos lugares.

$\bigcirc$ próprio Estado, nesse caso, desempenha funções importantes, sempre complexas e contraditórias. Ele pode, de um lado, promover a cidadania ao atuar com políticas públicas para garantir e disseminar direitos e, de outro lado, manter e mesmo produzir desigualdades espaciais. Estado brasileiro, em particular, durante o século XX, teve uma atuação muito próxima da lógica concentradora do mercado, sedimentando conhecidas desigualdades atuais (Almeida, 2005). Essa desigualdade acumulada no espaço, resultado de ações e objetos que foram tornando-se fixos no território e que dão suporte às ações, por exemplo, condiciona, limita e torna possível a eficácia e efetividade das políticas públicas. Entretanto, no final do século XX, a criação do SUS, resultado de intensas lutas sociais, foi um importante marco do Estado brasileiro para promoção da igualdade. Nesse sentido, o legado de uma estrutura territorial concentrada e concentradora de recursos, constituído ao longo do século XX, condiciona nossas opções políticas atuais.

\section{Concentração territorial em saúde: os recursos de imagem-diagnóstico}

Como vimos, a associação entre as diferentes variáveis (envelhecimento da população, ampliação da classe média, ampliação das doenças crônico-degenerativas, bem como a estreita ligação entre sistema de saúde e as dinâmicas de mercado) ampliou significativamente o interesse das grandes corporações produtoras de equipamentos médicos de imagem-diagnóstico pelo Brasil.

As transformações demográficas, associada a uma psicosfera que nos faz acreditar que a qualidade do serviço médico e a obtenção de saúde só são possíveis com o uso de aparelhos médicos sofisticados, têm favorecido a crescimento do número de equipamentos de resso- 
nância magnética e tomografia computadorizada nos consultórios médicos e hospitais. Se por um lado, aumenta o número de equipamentos, por outro, esse aumento é territorialmente concentrado. Essas características nos permitem dizer que o estudo da concentração desses equipamentos médicos no território brasileiro é um importante indicador das desigualdades em saúde no Brasil. Equipamentos médicos raros tendem a se localizar nos nós mais importantes da rede urbana, principalmente, onde há denso mercado consumidor, infraestrutura e redes que dão suporte ao seu funcionamento. Por isso, trata-se, também, de um importante indicador de centralidade urbana.

Para avaliar a distribuição territorial e evidenciar a concentração desses equipamentos médicos sofisticados no território, fizeram-se diversas análises por meio de técnicas de tratamento cartográfico e com o uso de ferramentas de geoprocessamento.

Para tanto, foram utilizados dados disponíveis no sistema Datasus (Departamento de Informática do SUS) do ano de 2010 e 2011, mapeados por município e organizados segundo diferentes critérios para avaliar a distribuição dos equipamentos no território brasileiro, seja levando em conta a tipologia de cidades, seja agregando por grandes região ou estabelecendo diferenças entre capitais e cidades do interior. Os equipamentos considerados no mapeamento englobam tanto equipamentos públicos quanto privados.

No primeiro caso, fez-se uma correlação entre a localização dos equipamentos e a tipologia de cidades com que o IBGE que, pela metodologia da Região de Influência das Cidades (Regic), estabelece uma hierarquia dos centros urbanos brasileiros. Os resultados mostraram a alta seletividade espacial na localização desses equipamentos médicos (Quadro 1).

\section{Quadro 1 - Distribuição dos equipamentos de ressonância magnética e tomografia computadorizada segundo a tipologia de cidades do IBGE}

\begin{tabular}{|c|c|c|c|c|c|}
\hline & $\begin{array}{c}\text { número } \\
\text { de cidades }\end{array}$ & $\begin{array}{c}\text { percentual } \\
\text { de cidades }\end{array}$ & $\begin{array}{c}\text { número de } \\
\text { equipamentos }\end{array}$ & $\begin{array}{c}\text { percentual de } \\
\text { equipamentos }\end{array}$ & $\begin{array}{c}\text { percentual } \\
\text { da população } \\
(2010)\end{array}$ \\
\hline $\begin{array}{c}\text { grande } \\
\text { metrópole } \\
\text { nacional }\end{array}$ & 1 & 0,02 & 359 & 8,76 & 5,89 \\
\hline $\begin{array}{c}\text { metrópole } \\
\text { nacional }\end{array}$ & 2 & 0,04 & 461 & 11,25 & 4,66 \\
\hline metrópole & 9 & 0,16 & 579 & 14,13 & 8,75 \\
\hline $\begin{array}{c}\text { capital regional } \\
\text { A }\end{array}$ & 11 & 0,20 & 332 & 8,10 & 4,21 \\
\hline $\begin{array}{c}\text { capital regional } \\
\text { B }\end{array}$ & 20 & 0,36 & 301 & 7,35 & 3,99 \\
\hline $\begin{array}{c}\text { capital regional } \\
\text { C }\end{array}$ & 39 & 0,70 & 404 & 9,86 & 5,46 \\
\hline total/média & 82 & 1,47 & 2436 & 59,44 & 32,96 \\
\hline
\end{tabular}

fonte: IBGE (2008, 2013); MS (2013). organização: Oseias S. Martinuci, 2013. 
De acordo com os dados do Cadastro Nacional de Estabelecimentos de Saúde (Cnes) do Ministério da Saúde, em novembro de 2011, existiam no Brasil 2.949 tomógrafos computadorizados e 1.149 equipamentos de ressonância magnética, num total de 4.098. Como vemos no Quadro 2, aproximadamente 60\% desses equipamentos se concentram em 82 cidades brasileiras. Em outras palavras, menos de $2 \%$ dos municípios brasileiros, onde vive um terço da população, concentra mais da metade dos equipamentos. É preciso considerar, entretanto, que há também concentração demográfica no território brasileiro. Mesmo assim, se nesses 82 centros urbanos concentram-se aproximadamente $60 \%$ dos equipamentos, a concentração populacional é quase metade disso, ou seja, 32,96\%.

A concentração desses equipamentos no território brasileiro acompanha a concentração dos principais centros urbanos. $\bigcirc$ mapa, forma privilegiada de comunicação de informações espaciais, é o recurso mais apropriado para mostrar a concentração de recursos sociais. No caso do Brasil, a concentração dos recursos sociais vem, frequentemente, acompanhada da desigualdade. Observando atentamente os Mapas 4 e 5, vemos que os equipamentos de ressonância magnética e tomografia computadorizada estão muitos presentes na porção do Brasil que Milton Santos e María Laura Silveira (2008) denominaram "região concentrada", uma área contínua composta pelas regiões Sul e Sudeste e parte do Centro-Oeste.

Os Mapas 4 e 5 permitem observar a localização dos equipamentos em manchas (a chamada região concentrada), em eixos (um que se estrutura do Sudeste até Porto Velho-RO e outro do Sudeste até Marabá-PA) e em pontos (como Manaus-AM e Macapá-AP).

Mapa 4 -

Ressonância magnética - 2010

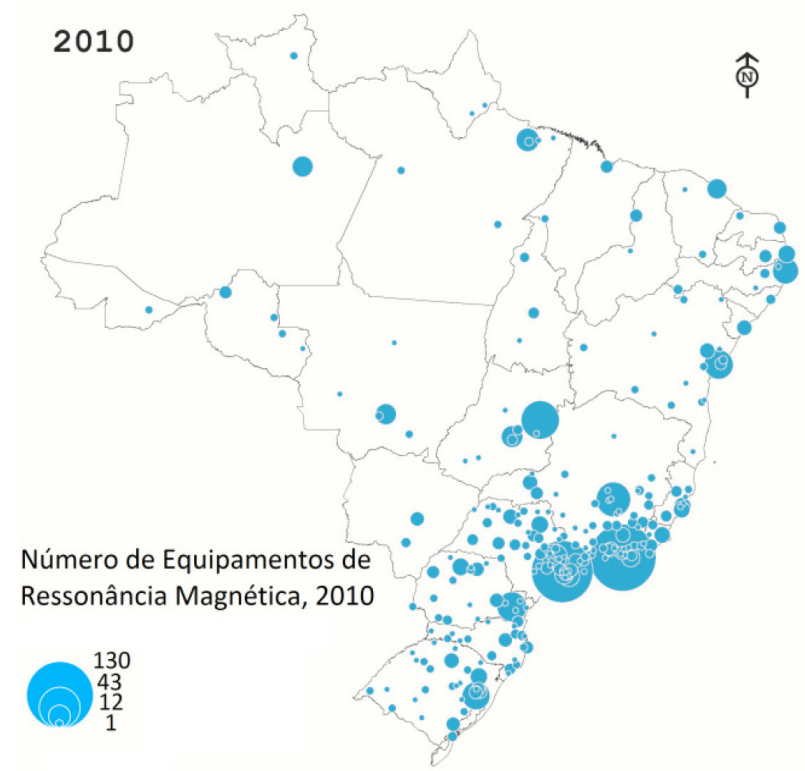

fonte: MS (2013).

\section{Mapa 5 -}

\section{Tomografia computadorizada -2010}

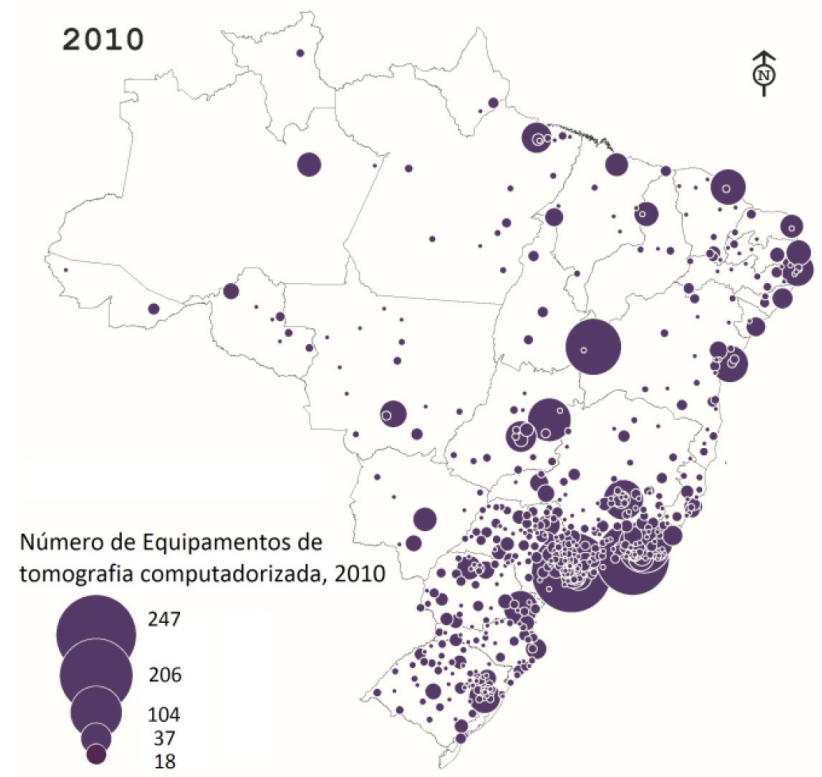

fonte: MS (2013).

organização: Oseias S. Martinuci, 2013. 
Quanto à disponibilização desses recursos de saúde à população brasileira, o Estado tem tido uma presença maior onde o mercado não tem despertado interesse, ou seja, onde há baixa densidade do mercado consumidor, da divisão social do trabalho e falta de infraestrutura. $\bigcirc$ Quadro 2 foi construído com a intenção de verificar o peso do público em diferentes regiões e entre capitais e cidades do interior.

\section{Quadro 2 - Percentual de equipamentos (RM e TC) disponíveis ao SUS conforme capitais e cidades do interior segundo a região - 2010}

\begin{tabular}{|l|c|l|c|}
\hline \multicolumn{2}{|c|}{ capitais } & \multicolumn{2}{c|}{ interior } \\
\hline região & $\begin{array}{c}\text { percentual de equipamentos } \\
\text { disponíveis ao SUS (\%) }\end{array}$ & região & $\begin{array}{c}\text { percentual de equipamentos } \\
\text { disponíveis ao SUS }\end{array}$ \\
\hline Norte & 61,90 & Norte & 66,67 \\
\hline Nordeste & 48,86 & Nordeste & 59,57 \\
\hline Centro-Oeste & 31,60 & Centro-Oeste & 59,41 \\
\hline Sudeste & 21,55 & Sudeste & 45,79 \\
\hline Sul & 39,74 & Sul & 65,92 \\
\hline Brasil & 33,47 & Brasil & 53,57 \\
\hline
\end{tabular}

organização: Oseias S. Martinuci, 2013.

Em função de diferentes condições demográficas, econômicas, sociais e políticas, as regiões do Brasil se caracterizam com diversos graus de dependência dos serviços públicos de saúde. É marcante, portanto, o fato de as regiões Norte e Nordeste do país serem altamente dependente da rede pública, uma vez que os equipamentos disponíveis ao SUS podem chegar a 70,17\%, no caso da ressonância magnética. Certamente, o papel do Estado nessas regiões é extremamente importante como agente capaz de disseminar direitos sociais tão fundamentais como os relativos às políticas de saúde, principalmente no curso das últimas décadas, quando a urbanização, o envelhecimento da população, a mudança de hábitos alimentares e também das atividades laborais tornam cada vez mais necessários alguns instrumentos de detecção precoce de doenças. É preciso garantir não apenas a presença desses modernos objetos médicos, mas também o acesso a eles, principalmente em regiões onde os deslocamentos são bastante difíceis para a população que tem sua mobilidade reduzida em função de condições socioeconômicas e espaciais.

Tomando o conjunto de dados do Quadro 2, verifica-se que, em termos gerais, as cidades do interior dependem mais do SUS do que as capitais. $\bigcirc$ interior tem mais da metade de seus equipamentos disponíveis no SUS (53,57\%), enquanto as capitais têm apenas um quarto $(24,5 \%)$. Ou seja, cidades do interior dependem do SUS duas vezes mais que as capitais.

Apesar do aumento do número de equipamentos, há vazios em várias regiões do Brasil, onde o Estado não tem conseguido dar provimento adequado. Análises feitas por geoprocessamento com ferramentas de geração de buffer (padronizados em $200 \mathrm{~km}$ ) sugerem que há um percentual significativo da população fora do alcance das redes de cuidados de saúde, comprometendo seriamente a universalidade do atendimento. Essas análises indicaram que em 
2010, mais de 15 milhões de brasileiros, residentes em 792 municípios, estão fora do raio de cobertura dos centros prestadores de serviços de imagem-diagnóstico por ressonância magnética, enquanto quase quatro milhões, residentes em 204 municípios, estão fora do alcance dos centros que possuem tomógrafos computadorizados.

Os dados gerais para o Brasil indicam que a proporção de equipamentos por população melhorou muito (Quadro 3).

\section{Quadro 3 - Relação de equipamentos de imagem-diagnóstico por número de habitantes - 1999-2010}

\begin{tabular}{|l|c|c|c|c|}
\hline & $\begin{array}{c}\text { tomógrafos computadorizados } \\
\text { por } 100 \text { mil habitantes }\end{array}$ & \multicolumn{2}{c|}{$\begin{array}{c}\text { ressonância magnética } \\
\text { por 500 mil habitantes }\end{array}$} \\
\hline região & 1999 & 2010 & 1999 & 2010 \\
\hline Norte & 0,40 & 0,89 & 0,25 & 1,80 \\
\hline Nordeste & 0,56 & 0,92 & 0,45 & 1,33 \\
\hline Sudeste & 1,35 & 1,81 & 1,26 & 3,77 \\
\hline Sul & 0,81 & 1,77 & 0,86 & 3,76 \\
\hline Centro-Oeste & 0,95 & 1,71 & 1,02 & 3,27 \\
\hline Brasil & 0,81 & 1,47 & 0,77 & 2,89 \\
\hline
\end{tabular}

fonte: MS (2013); IBGE (2013). organização: Oseias S. Martinuci, 2013.

Seguindo orientações da Organização Mundial da Saúde (OMS), a Portaria n. 1.101 (MS, 2002) estabelece que a razão de tomógrafos computadorizados deve ser de 1 para cada 100 mil habitantes, enquanto para os equipamentos de ressonância magnética a relação recomendada é de 1 para 500 mil. $\bigcirc$ Quadro 3 foi construído a partir de relatórios do IBGE sobre saúde suplementar e dados do Datasus, considerando o início das séries até o ano de 2010. Nesses termos, verifica-se que, tomada as médias regionais, a razão de equipamentos de ressonância magnética está acima da recomendada, principalmente para as regiões Sul, Sudeste e Centro-Oeste. Por outro lado, a razão de tomógrafos computadorizados está abaixo da recomendação tanto no Norte quanto no Nordeste.

Na média nacional, a cobertura de tomógrafos computadorizados passou de 0,81 por cada 100 mil habitantes para 1,47, enquanto a cobertura de ressonância magnética passou de 0,77 para 2,89 por cada 500 mil habitantes, evidenciando a ampliação da cobertura no Brasil. Por outro lado, em termos geográficos, em função da concentração de recursos, constatamos que uma parte importante da população brasileira residente no interior do país, está muito distante dos centros prestadores desses serviços especializados, comprometendo a acessibilidade.

Além disso, é interessante notar que a razão de equipamentos de ressonância magnética, sendo uma tecnologia mais recente, cujos objetos são, também, mais raros e com custos mais elevados para sua aquisição, superou a recomendação da Portaria n. 1.101/2002, enquanto o tomógrafo computadorizado ainda apresenta problemas de cobertura. Vê-se que a estrutura territorial brasileira, concentrada e concentradora, tende a gerar mais concentrações e impor obstáculos ao atendimento equitativo da população. 
Como afirma Milton Santos (2008, p. 167), velhas localizações atraem novas localizações. A atual distribuição dos equipamentos de imagem-diagnóstico, em particular os de ressonância magnética e tomografia computadorizada foi condicionada pela concentração de objetos, técnicas e ações no espaço, historicamente determinados, e, ao mesmo tempo, um condicionante de novas localizações. Por essa razão, a formulação de políticas públicas que visem garantir o princípios fundamentais do SUS, previstos na Constituição Federal de 1988, não podem ignorar a configuração dos sistemas técnicos no território, principalmente num momento em que se amplia o sistemismo das novas tecnologias médicas.

\title{
Considerações finais
}

Conforme o estudo da distribuição de equipamentos de apoio diagnóstico de alta complexidade pelo território brasileiro, pode-se concluir que a saúde brasileira funciona como um setor lucrativo da economia nacional e mundial, atraindo o interesse de poderosos agentes econômicos, que acompanham com atenção as mudanças pelas quais o país tem passado nos últimos anos.

Mais do que nunca, a leitura geográfica do tema é de extrema relevância, uma vez que fornece parâmetros analíticos para se compreender a incorporação dessas inovações na área da medicina, representadas em grande parte por objetos carregados de ciência, tecnologia e informação crescentemente associados a elementos das redes urbana, energética, de informação e comunicação e de transportes. Os sistemas de fixos e fluxos gerados por essas inovações reforçam a estruturação desigual do espaço nacional acentuando a desigual distribuição de objetos e de ações de saúde no Brasil e comprometendo os princípios constitucionais da universalidade, da integralidade e da equidade da saúde.

Esses resultados foram obtidos pela aplicação de conceitos geográficos à análise de dados do Datasus (principal banco de dados da saúde brasileira) acerca do uso de serviços, com destaque para o conceito de situação geográfica. A interpretação dos dados por meio da representação cartográfica mostrou-se necessária e relevante, dando uma visão integrada do tema a partir da localização e da distribuição dos equipamentos pelo território nacional.

Assim, o fortalecimento e a ampliação da cidadania no Brasil passa pela consideração do território na formulação, implementação e avaliação das políticas públicas criadas para promover os direitos sociais, em especial, o direito à saúde. Avançar no sentido da igualdade territorial em saúde é um importante passo para promover a igualdade em geral, pois seus efeitos tendem a se propagar em outras esferas da vida social, e a geografia ainda tem muito a contribuir para essas questões.

\section{Referências}

ABDI. AGÊNCIA BRASILEIRA DE DESENVOLVIMENTO INDUSTRIAL. Panorama setorial: equipamentos médicos, hospitalares e odontológicos. Brasilia, DF: ABDI, 2008.

\author{
ALMEIDA, E. P. O uso do território brasileiro e os serviços de saúde no período téc- \\ nico-científico-informacional. Tese (Doutorado em Geografia Humana) - Faculdade \\ de Filosofia, Letras e Ciências Humanas, Universidade de São Paulo, São Paulo, 2005.
}


ANTAS JR., R. M; ALMEIDA, R. S. Diagnóstico médico e uso corporativo do território brasileiro. Saúde e Sociedade, São Paulo, v. 24, n. 2, p. 674-690, 2015.

ARENDT, H. A condição humana. 10. ed. Rio de Janeiro: Forense Universitária, 2008.

BARATA, R. B. Como e por que as desigualdades sociais fazem mal à saúde. 2. ed. Rio de Janeiro: Fiocruz, 2009.

. Desigualdades sociais em saúde. In: CAMPOS, G. W. S. (Org.) Tratado de saúde coletiva. Rio de Janeiro: Fiocruz, 2006.

BARROS, M. B. A. Desigualdade social em saúde: revisitando momentos e tendências nos 50 anos de publicação da RSP. Revista de Saúde Pública, São Paulo, v. 51, n. 17, 2017.

BOBBIO, N. A era dos direitos. Campus: Rio de Janeiro, 2004.

CATAIA, M. A.; RIBEIRO, L. H. L. Análise de situações geográficas. Revista da Anpege, v. 11, n. 15, p. 9-30, 2015.

CHAIMOWICZ, F. A saúde dos idosos brasileiros. Revista de Saúde Pública, São Paulo, v. 31, n. 2, p. 184-200, 1997.

COELHO, V. C. O esboço de uma diplomacia militar brasileira na África durante o governo Lula: oportunidades a indústria da defesa brasileira. In: SEMANA DE CIENCIAS HUMANAS, 6., 2010, Campos de Goytacazes. Anais... Campos de Goytacazes: Instituto Federal Fluminense, 2010. p. 269-277.

DAVID, V. C. O território usado e o circuito superior marginal. Dissertação (Mestrado em Geografia Humana) - Faculdade de Filosofia, Letras e Ciências Humanas, Universidade de São Paulo, São Paulo, 2011.

FRENK, J. et al. La transición epidemiológica en América Latina. Boletín de la Oficina Sanitaria Pan-Americana, Washington, v. 111, n. 6, p. 485-496, 1991.

GUIMARÃES, R. B. Geografia e saúde coletiva no brasil. Saúde e Sociedade, São Paulo, v. 25, n. 4, p. 869-879, 2016.

Políticas de salud y escala geográfica. In: PICKENHAYN, J. (Org.). Salud y enfermedad. Buenos Aires: Lugar, 2009. p. 101-110.

HOUSE, J.; KESSELER, R.; REGULA, H. A. Age, socioeconomic status and health. Milbank Quarterly, New York, n. 3, p. 383-411, 1990.

IBGE. INSTITUTO BRASILEIRO DE GEOGRAFIA E ESTATISTICA. Sidra. Censo demográfico 2010 - Séries temporais. Disponível em: https://sidra.ibge.gov.br/pesquisa/censo-demografico/series-temporais/series-temporais/. Acesso em: nov. 2013.

Regiões de influência das cidades 2007. Rio de Janeiro: IBGE, 2008.

KOSIK, K. Dialética do concreto. 5. ed. Rio de Janeiro: Paz e Terra, 1989.

LACOSTE, Y. A geografia: isso serve, em primeiro lugar, para fazer a guerra. 14. ed. Campinas, SP: Papirus, 2008. 
LERNER, M. Modernization and health: a model of the health transition. Documento apresentado na Reunião Anual da American Public Health Association. São Francisco, CA, 1973. (Inédito.)

MARTINUCI, O. S. A compreensão geográfica dos eventos em saúde no território brasileiro e a análise cartográfica dos equipamentos de imagem-diagnóstico de alta complexidade. Tese (Doutorado em Produção do Espaço Geográfico) - Faculdade de Ciências e Tecnologia, Universidade Estadual Paulista, Presidente Prudente, 2013.

MORAIS, L.; SAAD-FILHO, A. Da economia política à política econômica: o novo desenvolvimentismo e o governo Lula. Revista de Economia Política, Porto Alegre, v. 31, n. 4 (124), p. 507-527, out./dez. 2011.

MOTA, A. Quem é bom já nasce feito. Rio de Janeiro: DPEA, 2003.

MS. MINISTÉRIO DA SAÚDE. Datasus 2013. Disponível em: www.datasus.gov.br. Acesso em: nov. 2013.

Portaria n. 1.101: parâmetros de cobertura assistencial no âmbito do Sistema Único de Saúde - SUS. Brasília, DF, 2002.

NERI, M. C. A nova classe média. Rio de Janeiro: FGV/lbre, 2010.

; SOARES, W. Desigualdade social e saúde no Brasil. Cadernos de Saúde Pública. Rio de Janeiro, v. 18 (suplemento), p. 77-87, 2002.

NOVAES, H. M. D.; NOVAES, R. F. Saúde, doença e inovação tecnológica. Saúde e Sociedade, São Paulo: Unifesp, v. 3, n.1, p. 61-78, 1994.

NUNES, B. P.; THUMÉ, E.; TOMASI, E.; DURO, S. M. S.; FACCHINI, L. A. Desigualdades socioeconômicas no acesso e qualidade da atenção nos serviços de saúde. Revista de Saúde Pública, São Paulo, n. 48, v. 6, p. 968-976, 2014.

OLIVEIRA, E. X. G.; CARVALHO, M. S.; TRAVASSOS, C. Acesso à internação hospitalar nos municípios brasileiros em 2000: territórios do Sistema Único de Saúde - mapeamento das redes de atenção hospitalar. Cadernos de Saúde Pública, Rio de Janeiro, v. 20, n. 2, p. S298-S309, mar./abr. 2004.

ORTEGA Y GASSET, J. Meditação da técnica. São Paulo: Ibero-Americano, 1963.

RIBEIRO, A. C. T. Território usado e humanismo concreto. In: SILVA, C. A. Formas em crise: utopias necessárias. Rio de Janeiro: Arquimedes, 2005. p. 93-111.

SANTOS, M. Por uma geografia nova. 6. ed. São Paulo: Edusp, 2008.

O espaço do cidadão. 7. ed. São Paulo: Edusp, 2007.

. $O$ papel da geografia: um manifesto. Revista Território, Rio de Janeiro, v. 5, n. 9 , p. 103-109, jul./dez. 2000.

A natureza do espaço. São Paulo: Hucitec, 1996. 
SANTOS, M.; RIBEIRO, A. C. T. O conceito de região concentrada. Rio de Janeiro: Departamento de Geografia/Ippur/UFRJ, 1979. (Mimeo.)

SANTOS, M.; SILVEIRA, M. L. O Brasil: território e sociedade no início do século XXI. São Paulo: Record, 2008.

SILVEIRA, M. L. Uma situação geográfica: do método à metodologia. Revista Território. Rio de Janeiro, v. 4, n. 6, p. 21-28, jan./jun. 1999.

SIMOMURA, V. L. Desigualdades sociais em saúde da população idosa na Região

Metropolitana de Campinas. Dissertação (Mestrado em Demografia) - Instituto de Filosofia e Ciências Humanas, Universidade Estadual de Campinas, Campinas, 2013.

SOUZA NETO, D. M. A política externa brasileira nos oito anos do governo Lula: legados e lições para a inserção do Brasil no mundo. In: PAULA, M. (Org.). "Nunca antes na história deste país"...? um balanço das políticas do governo Lula. Rio de Janeiro: Fundação Heinrich Boll, 2011. p. 99-115.

STIGLITZ, J. E. O preço da desigualdade. Lisboa: Bertrand, 2016.

TRAVASSOS, C.; VIACAVA, F.; FERNANDES, C.; ALMEIDA, C. M. Desigualdades geográficas e sociais na utilização dos serviços de saúde no Brasil. Ciência E Saúde Coletiva, Rio de Janeiro, n. 5, p. 133-149, 2000.

TRINDADE, E. Desenvolvimento da avaliação de tecnologia de saúde no mundo. Boletim do Instituto de Saúde. São Paulo, v. 14, n. 2, p. 135-142, maio 2013.

Apoio: Fundação de Amparo à Pesquisa do Estado de São Paulo (FAPESP) - Processo 2010/02475-8 